\title{
Escultura e iconografia tumular infantil no Rio Grande do Sul: -- uma metodologia em construção
}

\author{
Escultura e iconografía de tumbas infantiles en Rio Grande do Sul: una \\ metodología en construcción
}

\author{
Sculpture and children's tomb iconography in Rio Grande do Sul: a \\ methodology under development
}

Amanda Basilio Santos ${ }^{1}$

\begin{abstract}
Resumo
Esta pesquisa em desenvolvimento no Programa de Doutorado do curso de Memória Social e Patrimônio Cultural (PPGMP-UFPEL) intenciona realizar o levantamento e a análise da icono-grafia de monumentos tumulares infantis de crianças falecidas até os sete anos de idade, e erguidos no Rio Grande do Sul entre os séculos XIX e XXI. A análise será composta pelo estudo dos elementos fotográficos e escultóricos, assim como do epitáfio e dados biográficos dos objetos, que compõe o monumento funerário. Em nossa pesquisa iremos abordar tais monumentos considerando sua materialidade, visualidade, espacialidade e significado sociocultural. O objetivo deste artigo, portanto, é explorar as possibilidades metodológicas atualmente pensadas nessa pesquisa para a exploração desse campo e a construção de um banco de fontes.

Palavras-Chave: Iconografia tumular; História da Infância; Metodologia de Pesquisa.
\end{abstract}

\section{Resumen}

Esta investigación en desarrollo en el Programa de Doctorado del curso de Memoria Social y Patrimonio Cultural (PPGMP-UFPEL) tiene la intención de llevar a cabo la encuesta y el análisis de la iconografía de las lápidas infantiles de niños que murieron hasta los siete años y se erigieron en Río Grande do Sur entre los siglos XIX y XXI. El análisis consistirá en el estudio de elementos fotográficos y escultóricos, así como el epitafio y los datos biográficos de los objetos que componen el monumento funerario. En nuestra investigación abordaremos estos monumentos teniendo en cuenta su materialidad, visualidad, espacialidad y significado sociocultural. El objetivo de este artículo, por lo tanto, es explorar las posibilidades metodológicas actualmente consideradas en esta investigación para la exploración de este campo y la construcción de un banco fuente.

Palabras claves: Iconografía de la tumba; Historia de la infancia; Metodología de investigación.

\section{Abstract}

This research under development in the Doctoral Program of the Social Memory and Cultural Heritage course (PPGMP-UFPEL) intends to carry out the survey and analysis of the iconography of infantile tomb monuments of children who died up to the age of seven, and erected in Rio Grande do South between the 19th and 21st centuries. The analysis will consist of the study of photographic and sculptural elements, as well as the epitaph and biographical data of the objects, which make up the funerary monument. In our research we will address these monuments considering their materiality, visuality, spatiality and socio-cultural significance. The objective of this article, therefore, is to explore the methodological possibilities currently considered in this research for the exploration of this field and the construction of a database.

Keywords: Tomb iconography; Childhood History; Research Methodology.

\footnotetext{
${ }^{1}$ Mestre em História (PPGH-UFPEL) -; Mestre em Memória Social e Patrimônio Cultural (PPGMP - UFPEL); Especialista em Artes (PPGA - UFPEL). Atualmente doutoranda em História (PPGH - UFRGS) e doutoranda em Memória Social e Patrimônio Cultural (PPGMP-UFPEL). Pelotas, Rio Grande do Sul, Brasil. E-mail: amanda_hatsh@yahoo.com.br. O presente trabalho está sendo realizado com apoio da Coordenação de Aperfeiçoamento de Pessoal de Nível Superior - Brasil (CAPES) - Código de Financiamento 001 This study is financed in part by the Coordenação de Aperfeiçoamento de Pessoal de Nível Superior - Brasil (CAPES) Finance Code 001.
} 


\section{Introdução}

Esta pesquisa intenciona realizar o levantamento e a análise da iconografia de monumentos tumulares infantis de crianças falecidas até os sete anos de idade, e erguidos no Rio Grande do Sul entre os séculos XIX e XXI, focando na análise de monumentos dos quatorze municípios mais antigos do Estado. A análise será composta pelo estudo dos elementos fotográficos e escultóricos, assim como do epitáfio e dados biográficos dos objetos, que compõe o monumento funerário. Em nossa pesquisa iremos abordar tais monumentos considerando sua materialidade, visualidade, espacialidade e significado sociocultural.

A morte e o enterramento são estágios fundamentais da convivência humana, compartilhados e vividos socialmente, sendo assim ritualizados. Os ritos incluem as ações, assim como a cultura material e visual que são utilizadas para que se deem suas performances. Por exemplo, por meio do batismo, é realizada a inclusão do sujeito na comunidade cristã, sendo um significativo momento de passagem, onde há a purificação do pecado original e o comprometimento dos responsáveis pela formação do sujeito dentro dos preceitos da comunidade cristã. Já por meio do ato funerário se dá a efetiva separação entre os vivos e os mortos, havendo uma presença fulcral da cultura material para compor os ritos desta passagem, amenizando a dor dos vivos e honrando a memória dos mortos.

Deste modo, compreendendo a representação infantil dentro do ambiente cemiterial, temos uma oportunidade de entendimento do papel social da criança, que se altera no tempo, assim como a escultura tumular e a construção da memória social da infância. Acompanhando estas modificações, e as escolhas feitas pelos familiares e pelos artistas para o estabelecimento da memória infantil após a perda nos permite refletir sobre a identidade e o papel atribuído para as crianças.

\section{Como estudar iconografia tumular infantil: uma proposta metodológica}

A metodologia para execução desta pesquisa será composta por três fases: Exploratória, Qualitativa e Iconológica, levando em consideração as particularidades da Cultura Material dos monumentos tumulares. Dado aos poucos estudos envolvendo iconografia funerária infantil no estado do Rio Grande do Sul, partiremos primeiramente com a fase Exploratória, onde será feita uma aproximação entre a fonte analisada e o conjunto bibliográfico, assim como feito um levantamento documental que nos permita fazer uma seleção de fontes dentro dos espaços cemiteriais, efetuando assim o levantamento da 
amostragem que irá compor o conjunto final de fontes. Ainda na fase exploratória, serão realizadas as visitações in situ aos quatorze cemitérios mais antigos do estado do RS.

A segunda fase será composta pela seleção final do conjunto de fontes por meio de amostragem do conjunto total dos monumentos cemiteriais e, por fim, sua análise iconológica. Dado que consideramos impossível efetuar a análise da totalidade de monumentos tumulares infantis no RS para o recorte temporal estabelecido em uma pesquisa planejada para ser executada em quatro anos, será necessário efetuar uma seleção para aprofundamento analítico. Deste modo, seguiremos os critérios abordados no subtítulo dedicado às fontes de pesquisa.

Por fim, iremos aplicar a metodologia de Panofsky - foco do nosso artigo - para a análise dos monumentos tumulares selecionados, sempre valorizando três níveis que compõe nosso objeto de pesquisa: a instância material (tangível), visual (artística) e intangível (sociocultural). O que propomos é uma análise que una sempre a iconografia ao seu suporte, a colocando em conexão com sua disposição espacial, neste caso, seu posicionamento na malha cemiterial e a disposição dos elementos fotográficos e esculturais na construção tumular.

O método proposto por Erwin Panofsky, tal como o conhecemos atualmente, foi formulado após já ter sido efetuadas práticas de análise de imagem por Panofsky, sendo assim, podemos dizer que a prática precedeu a teoria (MOLINA, 2010, p. 41). O ensaio escrito por Panofsky em 1921, sob o título “A História da Teoria das Proporções Humanas como Reflexo da História dos Estilos", trata-se de um ensaio de análise prática, sendo que já antecede e nos traz elementos que só serão organizados e esquematizados em um ensaio mais tardio, que seria publicado em 1939, e que se tornaria um de seus trabalhos mais conhecidos, se não o mais conhecido, "Iconografia e Iconologia: uma introdução ao estudo da Arte na Renascença". Porém, ele já havia tentado apresentar a formulação de seu método anteriormente:

Panofsky confronted the difficult task of presenting his method theoretically four times, twice while he was still in Germany (in the introduction to a collection of essays, Hercules am Scheideweg that appeared in 1930, and in an article in the journal Logos of 1932) and twice in the USA (in the introduction of Studies in Iconology of 1939, and, finally in a chapter in Meaning in the Visual Arts). ${ }^{2}$ (HATT; KLONK, apud MOLINA, 2010, p. 25)

\footnotetext{
${ }^{2}$ Tradução da Autora: "Panofsky enfrentou a difícil tarefa de apresentar o seu método teoricamente quatro vezes, duas vezes enquanto ele ainda estava na Alemanha (na introdução de uma coletânea de ensaios, Hercules am Scheideweg que foi publicado em 1930, e em um artigo na revista Logos de 1932) e duas vezes nos EUA (na introdução de Estudos em iconologia de 1939, e, finalmente, em um capítulo do livro Significado nas Artes Visuais).
} 
Na sua metodologia temos três níveis analíticos, porém, que são intercambiáveis. Cada nível é atribuído um tipo de análise e um tipo de significado: primeiramente o préiconográfico que possui um "significado natural", sendo necessário restringir-se a elencar os elementos pertencentes a obra iconográfica, como mera identificação de objetos; o iconográfico que está ligado ao "significado convencional” no qual deve-se distinguir-se as cenas, reconhecer a narrativa geral, o que já pressupõe um arcabouço cultural maior que o primeiro nível que permita tal reconhecimento e, por fim, o iconológico, este voltado ao "significado intrínseco", principal objetivo dentro da análise de Panofsky. Conforme podemos ver na Tabela (Tabela 1) criamos um organograma que organiza as etapas e suas especificações, que são compost-as por capacidades e necessidades diferenciadas dependendo do momento analítico.
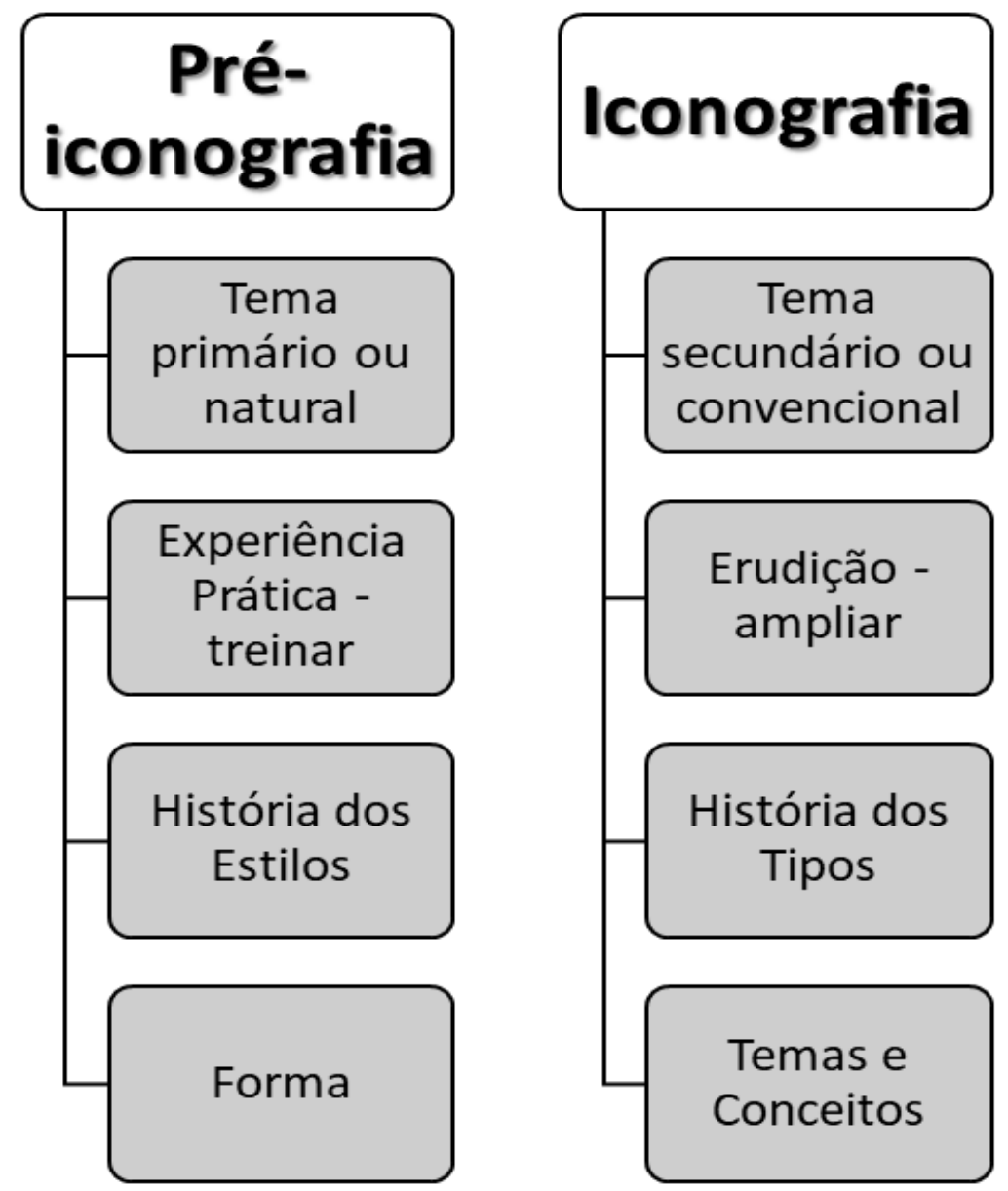

\section{Iconologia}

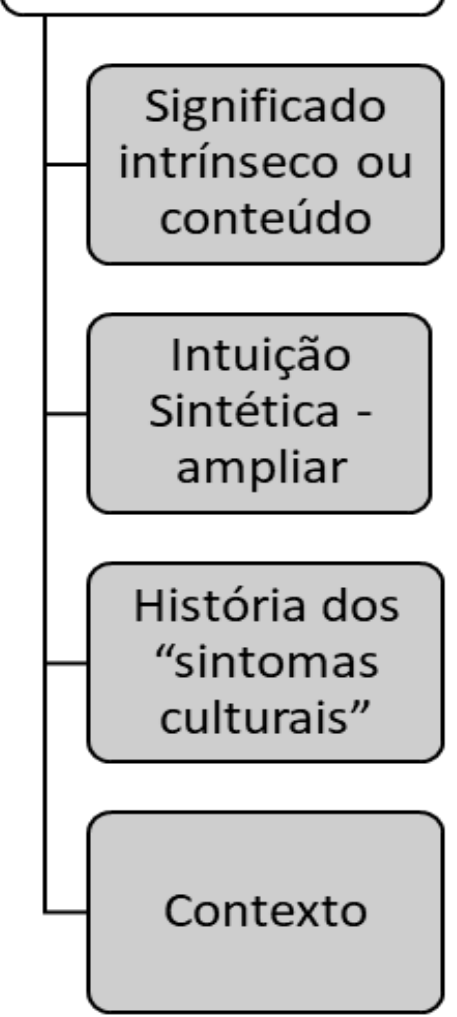

Tabela 1: Fases do processo de análise iconográfico proposto por Erwin Panofsky. Fonte: Autora.

De modo mais minucioso, o primeiro passo do método analítico parte da experiência e do reconhecimento e enumeração dos tipos pictóricos que estão distribuídos pela imagem, ou seja, "o mundo das formas puras assim reconhecidas como portadoras de significados 
primários ou naturais pode ser chamado de mundo dos motivos artísticos. Uma enumeração desses motivos constituiria a descrição pré-iconográfica de uma obra de arte." (PANOFSKY, 1979, p. 50).

É no momento pré-iconográfico que deve ser feita a identificação do tema primário puramente através da identificação visual das formas, e está diretamente ligado ao conhecimento da História dos estilos, através da sapiência de como em diferentes momentos históricos certos objetos foram representados, para que então seja possível a correta tipificação. Para que tal ambição seja alcançada é necessário que a experiência prática da qual nos fala Panofsky seja treinada, pois os mesmos elementos são representados de modo diferente através do tempo e o olhar deve ser treinado para reconhecimento destes detalhes.

O segundo momento da análise deve se focar na mensagem em contraposição à forma, esta seria a função da iconografia. Como podemos ver no primeiro momento a análise é ainda bastante tradicional, se levarmos em consideração a metodologia do campo da História da Arte, sendo determinado na descrição e identificação dos elementos visuais. Neste momento entra-se na esfera das alegorias, como é explicado por Panofsky sobre o reconhecimento das mensagens construídas através delas:

Por fim, o que se propõe é unir a forma ao conteúdo e ao contexto histórico em que foi produzido, de modo que a fonte imagética deixe de ter um papel secundário como ilustração e que ao mesmo tempo não possua uma aura de independência da sociedade que a produziu. Para cumprir tal objetivo será fundamental a metodologia de Erwin Panofsky, desde a composição do banco de dados, momento em que se utilizará a primeira etapa de sua metodologia (descrição pré-iconográfica), até a interpretação dos elementos simbólicos (iconologia). Antes de efetuar a análise iconográfica segundo a metodologia acima disposta, iremos efetuar a criação de um banco de dados, de natureza inventarial, para organizar o conjunto de fontes e permitir a disponibilização deste conjunto para auxiliar demais estudos.

\footnotetext{
-Assim fazendo, ligamos os motivos artísticos e as combinações dos motivos artísticos (composições) com assuntos e conceitos. Motivos reconhecidos como portadores de um significado secundário ou convencional podem chamar-se imagens, sendo que combinações de imagens são o que os antigos teóricos de arte chamavam de invenzioni; nós costumamos dar-lhes o nome de estórias e alegorias. (PANOFSKY, 1991, p. 50-51)
}

Panofsky sublinha sempre que a iconografia é a contraposição da mensagem aos aspectos técnicos e formais, pois no mundo das alegorias a imagem que vemos não significa o objeto representado, mas sim um significado convencionado, por isso este passo também é 
nomeado como a análise do tema secundário ou convencional, pois extrapola o mundo visual, entrando no mundo do simbólico. O entendimento do mundo simbólico e do significado secundário só é alcançado através da erudição, que o pesquisador deve constantemente ampliar, pois neste estágio é necessário o domínio da história dos tipos e da capacidade de discernir como em diferentes estágios históricos, assim como em diferentes localidades, os temas foram representados e através de quais motivos especificamente (PANOFSKY, 1991, p. 53).

A importância da iconografia para o terceiro passo do processo analítico de Panofsky é essencial, pois "a iconografia é de auxílio incalculável para o estabelecimento de datas, origens e, às vezes, autenticidade; e fornece as bases necessárias para quaisquer interpretações ulteriores.” (PANOFSKY, 1991, p. 53). Por fim, alcançamos a iconologia. Neste momento adentramos na análise da mensagem intrínseca, ou conteúdo que:

É apreendido pela determinação daqueles princípios subjacentes que revelam a atitude básica de uma nação, de um período, classe social, crença religiosa ou filosófica - qualificados por uma personalidade e condensados numa obra. Não é preciso dizer que estes princípios se manifestam, e portanto, esclarecem, quer através dos 'métodos de composição', quer da 'significação iconográfica'. (PANOFSKY, 1991, p. 52)

Este parece ser o momento mais confortável para o historiador, devendo interpretar a imagem inserindo-a em seu contexto histórico. A iconologia nos permite compreender a imagem enquanto documento e sintoma de um período, auxiliando a responder os problemas históricos levantados pelos pesquisadores, é a parte do processo que se ocupa dos valores simbólicos, que seria a forma de "concebermos assim as formas puras, os motivos, imagens, estórias e alegorias, como manifestações de princípios básicos e gerais. " (PANOFSKY, 1991, p. 52), é deste modo, o estudo dos sintomas culturais. Após feito a descrição iconográfica que "coleta e classifica a evidência" (PANOFSKY, 1991, p. 53), a iconologia deve ser direcionada para a análise de significado e de origem de tal evidência, buscando nas mais variadas partes da realidade humana o auxílio para sua compreensão, assim sendo, deve-se compreender o contexto filosófico, religioso, econômico, político, preferências individuais e dos patronos, assim como os conceitos abstratos e sua personificação palpável.

Para tornar sua metodologia mais compreensível, Panofsky nos apresenta com um exemplo do cotidiano, hoje já famoso, do homem que retira seu chapéu ao passar por outro na rua. O reconhecimento do gesto se dá através da percepção de mudanças na forma do homem (pré-iconografia) o que nos denuncia o gesto. O fato de ser um cumprimento é reconhecível 
por conta do conhecimento que temos do gesto, que é formado por uma cortesia que é convencionada, sendo assim se ultrapassa o gesto que é algo prático, para uma compreensão de algo imbuído nos costumes e na tradição que traz um significado específico (iconografia), porém, para um observador mais experiente é possível ultrapassar o reconhecimento do gesto e do significado da convenção: é possível visualizar componentes da personalidade ao autor do gesto, verificando-se que trata-se para além de um homem, um homem do século XX, que possui uma base nacional, educacional e social específica (iconologia) (PANOFSKY, 1991, p. 47-49).

Como colocamos ao iniciar esta discussão este é um método de três fases, ou seja, tripartido, porém ele é indivisível. Panofsky destaca que seu método é imbricado, e com a prática estas diferentes fases acabam se estreitando e ocorrendo simultaneamente. Concluímos que é um método indivisível, pois para que uma análise iconográfica seja feita de modo correto é fundamental que o tema primário tenha sido identificado de modo preciso e a análise iconológica só pode ser efetuada adequadamente com a correta identificação dos estilos e dos tipos, sendo assim, cada passo do próximo é dependente entre si, assim como ocorre de modo simultâneo, resumindo, "assim como a exata identificação dos motivos é o requisito básico de uma correta análise iconográfica, também a exata análise das imagens, estórias e alegorias é o requisito essencial para uma correta interpretação iconológica.” (PANOFSKY, 1991, p. 54).

Pretendemos, portanto, explorar esse método tripartido para analisar diferentes componentes visuais que em conjunto formam o memorial tumular, no caso de nossa pesquisa, os túmulos infantis.

\section{Considerações finais}

O objetivo deste artigo foi aprofundar-se no método proposto por Erwin Panofsky para este ser aplicado como um método para a análise do universo visual. Este projeto se justifica, em primeiro lugar, pela escassez constatada durante o nosso levantamento bibliográfico no que concerne aos estudos cemiteriais do Rio Grande do Sul para com os monumentos tumulares infantis. Deste modo, esta pesquisa se pretende como uma contribuição para o levantamento e estudo do patrimônio cemiterial do RS, ao mesmo tempo buscando valorizar este patrimônio, e contribuir para a compreensão sociocultural que cerca os rituais de enterramento infantil, em um recorte temporal de longa duração, permitindo assim interpretar as alterações e permanências neste processo ao longo do tempo (respeitando o recorte temporal estabelecido no projeto). As pesquisas cemiteriais no RS são, majoritariamente, de 
mapeamento e de levantamento quantitativo, análise de simbologia e levantamentos genealógicos (ARAÚJO, 2006). Deste modo, este campo em plena expansão carece de maiores pesquisas que abarquem as múltiplas facetas que esta fonte - muitas vezes incompreendida - nos fornece para o campo sociocultural. Nossa análise parte, como nos diz Maristela Carneiro, "do pressuposto de que a simbologia cemiterial objetiva a expressão ou a transmissão dos valores culturais, para o estabelecimento e reafirmação, ainda que de forma fragmentária, das identidades e relações sociais" (CARNEIRO, 2012, p. 136). Os cemitérios, portanto, ocupam um local fulcral para o entendimento dos agentes sociais e do contexto cultural de sua produção, sendo universos visuais repletos de significados socioculturais.

\section{Referências}

ARAÚJO, T. N. Túmulos Celebrativos de Porto Alegre: múltiplos olhares sobre o espaço cemiterial (1889 - 1930). Porto Alegre: EDIPUCRS, 2008.

ARAÚJO, T. N. D. Espaço das representações da morte: Arte tumular como expressão da cultura. ANAIS DO IV ENCONTRO NACIONAL DO GT HISTÓRIA DAS RELIGIÕES E DAS RELIGIOSIDADES, Maringá, 5, n. 15, jan. 2013. 1-14. Disponivel em:

<http://www.dhi.uem.br/gtreligiao/pub.html>.

ARIÉS, P. História Social da Criança e da Família. Rio de Janeiro: Zahar Editores, v. 2, 1978 .

BURKE, P. Testemunha Ocular: História e Imagem. São Paulo: EDUSC, 2004.

CARNEIRO, M. Construções tumulares e representações de alteridade: materialidade e simbolismo no Cemitério Municipal de São José, Ponta Grossa/PR/BR 1881-2011. Revista Inter-Legere, 2013. 275-291.

CHARTIER, R. A história cultural: entre práticas e representações. Lisboa: Difel, 1990.

COELHO, A. M. Atitudes perante a morte. Coimbra: Livraria Minerva, 1991. 33-34 p.

GAWRYSZEWSKI, A. A representação da morte infantil em imagens cemiteriais no Brasil (séculos XIX e XX). História: Debates e Tendências, 16, n. 2, 2016. 291-313.

HALL, S. A identidade cultural na pós-modernidade. 11. ed. Rio de Janeiro: DP\&A Editora, 2006.

KOSSOY, B. Fotografia. In: ZANINI, W. História Geral da Arte no Brasil. São Paulo: Instituto Walther Moreira Salles, 1983. p. 869-913.

MOLINA, L. G. Da Prática à Teoria: o método Iconológico de Erwin Panofsky (1921, 1939, 1955). Porto Alegre: Universidade Federal do Rio Grande do Sul, 2010. 41f p. Monografia apresentada ao Curso de História da UFRGS.

NUCCI, N. A criança e a morte: um encontro existencial. In: SANTOS, F. S. A arte de morrer: visões plurais. São Paulo: Editora Comenius, v. 2, 2009. 
PANOFSKY, E. Significado nas Artes Visuais. São Paulo: Perspectiva, 1979.

PANOFSKY, E. Significado nas Artes Visuais. São Paulo: Perspectiva, 1991.

SILVA, T. T. (Ed.). Identidade e diferença: a perspectiva dos Estudos Culturais. 14. ed. Petrópolis: Vozes, 2014. 